\title{
Guidelines on Risk Factors for HIV Transmission Are Conflicting
}

\author{
Jiman He \\ Liver Research Center, Brown University, Providence, RI, USA \\ Email: hejee99@yahoo.com,jiman_he@brown.edu
}

How to cite this paper: He, J. (2020) Guidelines on Risk Factors for HIV Transmission Are Conflicting. World Journal of AIDS, 10, 195-199.

https://doi.org/10.4236/wja.2020.103017

Received: August 17, 2020

Accepted: September 15, 2020

Published: September 18, 2020

Copyright $\odot 2020$ by author(s) and Scientific Research Publishing Inc. This work is licensed under the Creative Commons Attribution International License (CC BY 4.0).

http://creativecommons.org/licenses/by/4.0/

\begin{abstract}
According to current guidelines, exposing mucous membrane to blood and body fluids of HIV infected people is risk of transmission. About $30 \%-80 \%$ of HIV infected people have at least one oral manifestation. The most frequently occurring oral manifestations (pseudomembranous candidiasis, linear gingival erythema, etc.) give rise to bleeding either spontaneously or after stimulation, and strenuous stirring during oral sex and deep-mouth kissing increase risk of bleeding from oral manifestations, exposing oral and genital mucous membrane of partners to the blood. However, current guidelines assert that there's little to no risk of getting HIV from oral sex and deep-mouth kissing. These guidelines are conflict with each other, suggesting potential problems with current prevention strategies which are based on the guidelines. After discussing existing data on animals, lesbians, young peoples, and occupational exposures, this paper suggests oral sex and deep-mouth kissing are risk factors when one partner has HIV-associated oral bleeding manifestations, and the number of infections associated with oral sex and deep-mouth kissing is significant. Current guidelines on HIV risk factors should be reevaluated urgently, and new studies should be undertaken with an open mind to explore risk factors.
\end{abstract}

\section{Keywords}

HIV, Transmission, Risk Factor, Guidelines, Oral Manifestation

\section{Introduction}

The number of new HIV infections per year in people aged $\geq 15$ years decreased by 0.5 million, from 2.3 million to 1.8 million, between 2000 and 2010, and decreased a further 0.2 million between 2010 and 2018/2019 [1]. This rate of the progress is too slow to reach the goal of eradicating AIDS by 2030, which is only 
a decade from now [2]. This paper shows that current guidelines on risk factors for HIV transmission are conflicting with each other, suggesting potential problems with our understanding of the risk factors for HIV transmission.

\section{Guidelines on HIV Risk Factors Are Conflicting}

The current guidelines on HIV prevention state that contact of mucous membrane (in the mouth, eye, etc.) with bloody body fluid of HIV infected people is a risk factor for HIV transmission, and recommend immediate flushing of the site with water [3] [4] [5].

About $30 \%-80 \%$ of HIV infected people have at least one oral manifestation [6]. The most frequently occurring manifestations (pseudomembranous candidiasis, linear gingival erythema, and severe periodontitis) [7] [8] [9] give rise to bleeding either spontaneously or after stimulation. Strenuous stirring during oral sex and deep-mouth kissing will increase bleeding from the oral lesions of HIV infected people. However, current guidelines state that "Oral sex is very unlikely to result in the transmission of HIV" [10]; "In general, there's little to no risk of getting HIV from oral sex" [11]; a person "cannot become infected or infect others" through Kissing [10]; and "In extremely rare cases, HIV has been transmitted" through deep kissing if both partners have sores or bleeding gums [11]. These guidelines statements directly contradict the statements that contact of mucous membrane with bloody body fluid is a risk factor for HIV transmission, and immediate water flushing is needed when the exposure occurs.

\section{Key Data Are Lacking}

Sexual intercourse, oral sex, and deep-mouth kissing commonly occur between partners. Although current guidelines state that HIV is mainly transmitted via sexual intercourse, and not or very rarely via oral sex/kissing, to my knowledge no study has collected data allowing a comparison of HIV transmission between partners who have sexual intercourse with oral sex/deep-mouth kissing and those who have sexual intercourse without oral sex/deep-mouth kissing, and no study has collected data allowing a comparison of the frequency of oral sex/deep-mouth kissing between infected partners and HIV positive patients with that between non-infected partners and HIV positive patients. Without these data, guidelines statements that HIV is not or very rarely transmitted via oral sex/kissing may be incorrect.

\section{Animal Data}

Simian immunodeficiency virus (SIV) is a recent ancestor of HIV. Studies in monkeys have shown that non-traumatic oral exposure to SIV resulted in infection [12] [13], with the minimum dose needed to infect monkeys orally being 6000-fold lower than via the rectum [13]. This high transmission efficiency after exposure of oral mucous membrane in animals may imply that, in humans, exposure of oral mucous membrane to HIV-positive blood carries a risk 
of transmission.

\section{Data on Occupational Exposures}

When occupational exposures to bloody body fluid occur, the exposed mucosa (in mouth, eye, etc.) is usually immediately washed with flushing water. Despite this, the risk of HIV transmission per mucosa exposure estimated by clinical data is still $0.09 \%$ [4].

\section{Data on Young People}

Rates of HIV infection are disproportionately high in people aged 15 - 25 years [14]. Mucosa exposure to HIV positive blood through kissing maybe one of the underlying reasons, because, for example, deep-mouth kissing occurs during courtship and early sexual relationships, but decreases after long-term marriage [15].

\section{Data on Lesbians}

Sex between lesbians has implications for the role of sexual intercourse and kissing in HIV transmission. Reviews on studies in the field have stated there is significant risk of HIV transmission in lesbians [16] [17]. There is a potential problem with the data interpretation of the studies in the field. During the studies, lesbians were asked whether they had an experience of sex with men or injection drug use. If the subject had such a history, the risk factor responsible for HIV infection was interpreted to be sexual intercourse or injection drug use. Therefore, the interpretation of the data was made based on an assumption that HIV is not or very rarely transmitted via oral sex and kissing. This approach will erase potential risk factors other than the recognized ones.

\section{Discussion}

Contradictions between the two groups of guidelines on HIV risk factors suggest potential problems with current concept on the risk factors for HIV transmission, and current prevention strategies which are based on the concept.

The risk of HIV transmission per oral or genital mucosa exposure to HIVcontaminated fluids during oral sex or deep-mouth kissing may exceed 0.09\% because the duration of the exposure is longer than that of an occupational exposure in which an exposed site is immediately flushed with water. Moreover, the volume of HIV-contaminated fluids exposed is greater than that in exposures in an occupational accident (e.g. a splash droplet).

Understanding the risk factors for HIV transmission is important to developing effective policies and programs to fight the disease. However, current guidelines on HIV risk factors are not consistent, and the key data needed to clarify this issue are lacking. In studies in which different risk factors for HIV infection may exist, the interpretation of the data was distorted by a reliance on the inconsistent guidelines. 


\section{Conclusion}

This paper suggests oral sex and deep-mouth kissing are risk factors when one partner has HIV-associated oral bleeding manifestations. Given that a significant number of people with HIV have oral bleeding manifestations, infections associated with oral sex and deep-mouth kissing would be expected to be significant. The guidelines on risk factors should be reevaluated, and studies should be undertaken urgently with an open mind to explore the risk factors.

\section{Acknowledgements}

The author received no specific funding for this work.

\section{Conflicts of Interest}

The author declares no conflicts of interest.

\section{References}

[1] UNAIDS (2019) Global HIV Statistics. https://www.unaids.org/sites/default/files/media_asset/UNAIDS_FactSheet_en.pdf

[2] Carter, M. (2016) Ending AIDS by 2030 a Distant Prospect, Global HIV Incidence, Prevalence, Treatment Coverage and Mortality Figures Suggest. AIDSmap. https://www.aidsmap.com/news/aug-2016/ending-aids-2030-distant-prospect-globa l-hiv-incidence-prevalence-treatment-coverage

[3] United States OSHA (2018) OSHA and the Bloodborne Pathogen Standard. https://oshaguard.com/blogs/news/bloodborne-pathogen-standard-and-osha

[4] Kuhar, D.T., et al. (2013) United States Public Health Service. Updated US Public Health Service Guidelines for the Management of Occupational Exposures to $\mathrm{Hu}$ man Immunodeficiency Virus and Recommendations for Postexposure Prophylaxis. Infection Control and Hospital Epidemiology, 34, 875-892. https://www.jstor.org/stable/10.1086/672271\#metadata_info_tab_contents

[5] United States CDC: Bloodborne Infectious Diseases: HIV/AIDS, Hepatitis B, Hepatitis C. https://www.cdc.gov/niosh/topics/bbp/emergnedl.html

[6] Saini, R. (2011) Oral Lesions: A True Clinical Indicator in Human Immunodeficiency Virus. Journal of Natural Science, Biology, and Medicine, 2, 145-150. https://doi.org/10.4103/0976-9668.92316

[7] Saravani, S., Nosratzehi, T., Kadeh, H., et al. (2017) Oral Manifestations and Related Factors of HIV Positive Patients in South-East of Iran. Journal of Dental Materials and Techniques, 6, 11-18.

[8] Coogan, M.M., Greenspan, J. and Challacombe, S.J. (2005) Oral Lesions in Infection with Human Immunodeficiency Virus. Bulletin of the World Health Organization, 83, 700-706

[9] Pakfetrat, A., Falaki, F., Delavarian, Z., et al. (2015) Oral Manifestations of Human Immunodeficiency Virus-Infected Patients. Iranian Journal of Otorhinolaryngology, 27, 43-54.

[10] UNAIDS. Living in a World with HIV. https://bangladesh.iom.int/sites/default/files/publication/Living-in-a-world-with-HI V-information-for-UN-system-personnel-and-their-families.pdf

[11] United States CDC. HIV Transmission. 
https://www.cdc.gov/hiv/basics/transmission.html

[12] Stahl-Hennig, C., Steinman, R.M., Tenner-Racz, K., et al. (1999) Rapid Infection of Oral Mucosal-Associated Lymphoid Tissue with Simian Immunodeficiency Virus. Science, 285, 126-125. https://doi.org/10.1126/science.285.5431.1261

[13] Baba, T.W., Trichel, A.M., An, L., et al. (1996) Infection and AIDS in Adult Macaques after Nontraumatic Oral Exposure to Cell-Free SIV. Science, 272, 1486-1489. https://doi.org/10.1126/science.272.5267.1486

[14] WHO. HIV and Youth. https://www.who.int/maternal_child_adolescent/topics/adolescence/hiv/en

[15] Descamps, B. 5 Reasons Married Couples Stop French Kissing. https://www.yourtango.com/experts/brenda-descamps/why-married-couples-stop-f rench-kissing

[16] Dworkin, S.L. (2005) Who Is Epidemiologically Fathomable in the HIV/AIDS Epidemic? Gender, Sexuality, and Intersectionality in Public Health. Cult Health Sex, 7, 615-623. https://doi.org/10.1080/13691050500100385

[17] Campbell, C. (1999) Women, Families, and HIV/AIDS. Cambridge University Press, New York. https://doi.org/10.1017/CBO9780511570988 